\title{
Crack D eflection and Propagation in Layered Silicon Nitride/Boron Nitride Ceramics
}

\author{
Desiderio Kovar, ${ }^{*}, t, \neq$ M. D. Thouless, ${ }^{*}, 8$ and John W. Halloran ${ }^{*}, t$ \\ Materials Science and Engineering Department and Mechanical Engineering and Applied Mechanics Department, \\ University of Michigan, Ann Arbor, Michigan 48109-2125
}

\begin{abstract}
Crack deflection and the subsequent growth of delamination cracks can be a potent source of energy dissipation during the fracture of layered ceramics. In this study, multilayered ceramics that consist of silicon nitride $\left(\mathrm{Si}_{3} \mathbf{N}_{4}\right)$ layers separated by boron nitride/silicon nitride $\left(\mathrm{BN}_{\mathbf{S}} \mathrm{Si}_{3} \mathrm{~N}_{4}\right)$ interphases have been manufactured and tested. Flexural tests reveal that the crack path is dependent on the composition of the interphase between the $\mathrm{Si}_{3} \mathrm{~N}_{4}$ layers. Experimental measurements of interfacial fracture resistance and frictional sliding resistance show that both quantities increase as the $\mathrm{Si}_{3} \mathrm{~N}_{4}$ content in the interphase increases. However, contrary to existing theories, high energyabsorption capacity has not been realized in materials that exhibit crack deflection but also have moderately high interfacial fracture resistance. Significant energy absorption has been measured only in materials with very low interfacial fracture resistance values. A method of predicting the critical value of the interfacial fracture resistance necessary to ensure a high energy-absorption capacity is presented.
\end{abstract}

\section{Introduction}

$\mathrm{I}^{\mathrm{i}}$

T HAS previously been shown that it is possible to fabricate layered ceramics that have high strength in combination with the ability to absorb large amounts of energy when tested in flexure. ${ }^{1-4}$ Because they can be manufactured from commercially available ceramic powders via conventional ceramic- and polymer-processing technology, the manufacturing costs for these materials ${ }^{5}$ can potentially be significantly lower than those for fiber-reinforced composites. Thus, layered ceramics can provide a low-cost alternative to fiber-reinforced composites when strength and energy absorption capabilities are limiting factors in the component design.

Silicon nitride $\left(\mathrm{Si}_{3} \mathrm{~N}_{4}\right)$ layered ceramics with weak boron nitride $(\mathrm{BN})$ interphases have been previously manufactured in a conventional two-dimensional layered structure, ${ }^{4}$ as well as in a novel layered structure known as a fibrous monolithic ceramic. ${ }^{6}$ Impressive properties were achieved for both structures, with strengths of $>600 \mathrm{MPa}$ and work-of-fracture (WOF) values of $\sim 8000 \mathrm{~J} / \mathrm{m}^{2}{ }^{7}$ These properties, as well as hightemperature strength and oxidation resistance, make this system attractive for commercial applications.

Many of the advantages that ceramic laminates have over monolithic ceramics result from crack deflection and propaga-

F. W. Zok-contributing editor

Manuscript No. 191231. Received February 4, 1997; approved July 21, 1997. Supported by DARPA, administered by the U.S. Office of Naval Research under Contract No. N0014-95-0302.

*Member, American Ceramic Society.

Materials Science and Engineering Department

Current address: Mechanical Engineering Department, The University of Texas at Austin, Austin, TX 78712-1063.

${ }^{\S}$ Mechanical Engineering and Applied Mechanics Department. tion that occur at weak interfaces or within weak interphases between the strong layers. Although several models exist that predict the conditions under which crack deflection should occur ${ }^{8-10}$ there is not much experimental data on all-ceramic systems to support these models. Even more importantly, it has been shown that, in some layered materials, delamination cracks kink out of the interface after propagating on the interface only a short distance. ${ }^{10,11}$ The result of such crack kinking is that not much energy is absorbed during the fracture of these materials. Thus, an understanding of the factors that control crack deflection and propagation along interfaces is needed to maximize the energy dissipation capabilities of layered ceramics.

In this paper, the mechanical properties of $\mathrm{Si}_{3} \mathrm{~N}_{4} / \mathrm{BN}$ multilayered ceramics are investigated. The properties of the interphase are adjusted by varying the composition of the $\mathrm{BN}$ interphase between the $\mathrm{Si}_{3} \mathrm{~N}_{4}$ layers. The strength and energy absorption of multilayered ceramics are measured, and the crack path is characterized as a function of the composition of the interphase.

\section{Fabrication of Specimens}

$\mathrm{Si}_{3} \mathrm{~N}_{4}$ powder (M-11, H. C. Starck, Newton, MA) was mixed with $2 \mathrm{wt} \%$ alumina $\left(\mathrm{Al}_{2} \mathrm{O}_{3}\right)$ (HC-HP DBM, Reynolds Metals Co., Bauxite, AZ) and 6 wt $\%$ yttria $\left(\mathrm{Y}_{2} \mathrm{O}_{3}\right)(99.9 \%$, Johnson Matthey Electronics, Ward Hill, MA) and ball milled for $24 \mathrm{~h}$ in ethanol. The slurry was dried and then compounded using an instrumented high-shear-rate mixer (Model PL-2000, C. W. Brabender, South Hackensack, NJ) with a thermoplastic copolymer binder that was composed of equal parts ethylenevinyl acetate (Elvax 470, E. I. DuPont De Nemours and Co. Wilmington, DE) and ethylene-ethyl acrylate (DPDA-6182, Union Carbide Chemicals and Plastics Co., Cleveland, $\mathrm{OH}$ ). The viscosity of the polymer/ceramic blend was controlled through the addition of a lubricant that consisted of a combination of mineral oil (white mineral oil-heavy, Mallinckrodt Chemicals, Paris, KY) and methoxy-polyethylene glycol (MPEG 550, Union Carbide, Danbury, CT). The total ceramic solids content in the compounds was varied from $37 \%$ to $51 \%$, which allowed the viscosity of the compounds to be varied by a factor of 2 .

To mold the materials into sheets, the polymer-ceramic compounds were chopped into blocks of material $\sim 1 \mathrm{~mm}$ long on each side and pressed between heated metal platens coated with aluminum foil and a lubricant (Carbowax 400, Union Carbide) at a temperature of $150^{\circ} \mathrm{C}$ under a pressure of 2.8 $\mathrm{MPa}$. The resulting sheets could be varied in thickness from $\sim 100 \mu \mathrm{m}$ to $800 \mu \mathrm{m}$, depending on the viscosity of the compounds and the pressure at which the sheet was pressed. For the current study, the thickness of the green sheets was fixed at $\sim 200 \mu \mathrm{m}$. After molding, the sheets were cut into rectangles that had dimensions of $51 \mathrm{~mm} \times 76 \mathrm{~mm}$.

To introduce weak interfaces between the $\mathrm{Si}_{3} \mathrm{~N}_{4}$ layers, the surface of each sheet was coated with a slurry that contained $\mathrm{BN}$. The composition of the $\mathrm{BN}$ layers was varied through the addition of $\mathrm{Si}_{3} \mathrm{~N}_{4}$ to the $\mathrm{BN}$ slurry. The slurries were made 


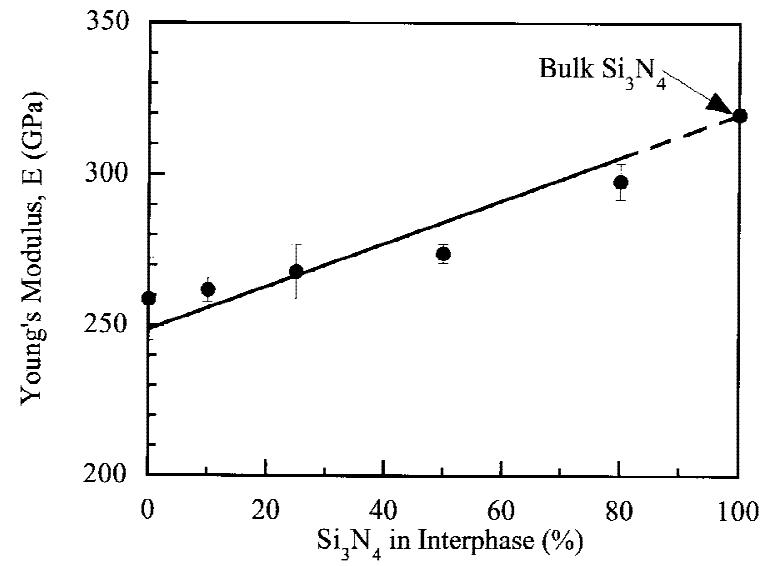

Fig. 1. Young's modulus $(E)$ of the layered ceramic, measured using the impulse-excitation technique, plotted versus $\mathrm{Si}_{3} \mathrm{~N}_{4}$ content in the interphase; the solid line is the rule-of-mixtures modulus. The value for bulk $\mathrm{Si}_{3} \mathrm{~N}_{4}$ has been taken from Kovar et al. ${ }^{11}$

from hexagonal $\mathrm{BN}$ (HCP, Advanced Ceramics Corp., Cleveland, $\mathrm{OH}), \mathrm{Si}_{3} \mathrm{~N}_{4}$, water, and ethanol. Individual billets were manufactured using interphases made from $0,10,20,50$, and $80 \mathrm{vol} \% \mathrm{Si}_{3} \mathrm{~N}_{4}$ (the remainder was $\mathrm{BN}$ ). After coating, the sheets were dried, stacked, and pressed at a temperature of $130^{\circ} \mathrm{C}$ under a pressure of $6.9 \mathrm{kPa}$ to mold them into a solid billet.

After forming the billet, the polymer binder was pyrolyzed by heating it slowly in a flowing nitrogen atmosphere. The heating rates were $60^{\circ} \mathrm{C} / \mathrm{h}$ to $150^{\circ} \mathrm{C}, 2^{\circ} \mathrm{C} / \mathrm{h}$ to $250^{\circ} \mathrm{C}, 4^{\circ} \mathrm{C} / \mathrm{h}$ to $370^{\circ} \mathrm{C}$, and $18^{\circ} \mathrm{C} / \mathrm{h}$ to $700^{\circ} \mathrm{C}$. A slow heating rate was necessary to minimize bloating and cracking during pyrolysis, which can result in distortion of the layers. After pyrolysis, the billets were placed in a $\mathrm{BN}$-coated graphite die and hot pressed at $1750^{\circ} \mathrm{C}$ for $2 \mathrm{~h}$ under a pressure of $25 \mathrm{MPa}$. Specimens for flexural tests were cut and ground from the billets to nominal dimensions of $3 \mathrm{~mm} \times 4 \mathrm{~mm} \times 50 \mathrm{~mm}$.

\section{Results}

After hot pressing, the thicknesses of the layers were measured on a polished surface of representative specimens using optical microscopy. The layer thicknesses were $116 \pm 34 \mu \mathrm{m}$ and $36 \pm 18 \mu \mathrm{m}$ for the $\mathrm{Si}_{3} \mathrm{~N}_{4}$ layers and the BN-containing interphases, respectively. X-ray diffractometry (XRD) indicated that all of the $\mathrm{Si}_{3} \mathrm{~N}_{4}$ transformed to $\beta-\mathrm{Si}_{3} \mathrm{~N}_{4}$ during hot pressing. Hexagonal $\mathrm{BN}$ and a very small amount of tetragonal zirconia $\left(\mathrm{t}-\mathrm{ZrO}_{2}\right)$ were also detected. The $\mathrm{ZrO}_{2}$ contamination resulted from the media used during the ball milling of the powders.

\section{(1) Young's Modulus}

The Young's modulus of the specimens was measured using an impulse-excitation technique (Grindo-Sonic MK4x, J. W. Lemmens, St. Louis, MO), according to ASTM Method C 1259-94. "I To verify that these results were valid for layered ceramics, the stiffness of selected specimens were also measured from the slope of load-deflection curves taken in the elastic regime in four-point bending. Specimen deflection at the center of the span was monitored using a linearly variable displacement transducer (LVDT) and corrected for the compliance of the machine, which had been determined previously. ${ }^{12}$

The Young's modulus $(E)$, determined using the pulsedexcitation technique, is plotted as a function of the $\mathrm{Si}_{3} \mathrm{~N}_{4}$ con-

\footnotetext{
"American Society for Standards and Testing, Philadelphia, PA.
}

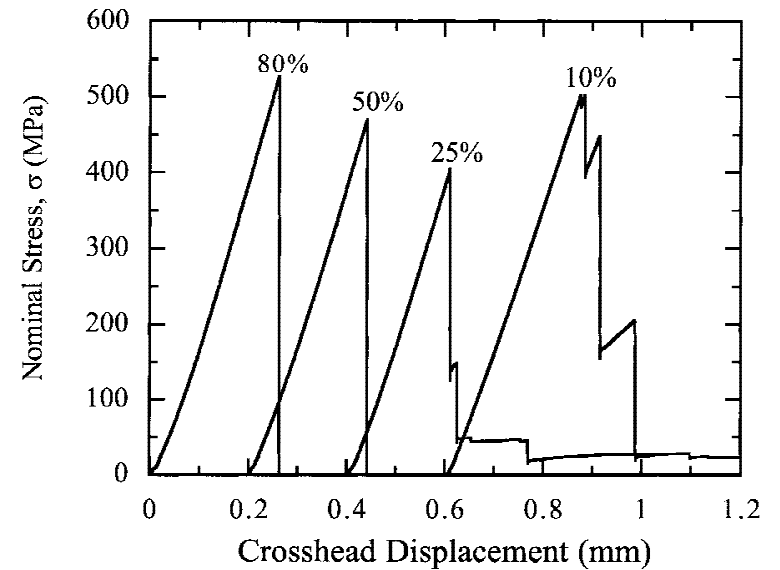

Fig. 2. Nominal tensile stress $(\sigma)$, plotted versus crosshead displacement, for specimens containing $10,25,50$, and $80 \mathrm{vol} \% \mathrm{Si}_{3} \mathrm{~N}_{4}$ in the interphase tested in four-point bending.

tent in the interphase in Fig. 1. The value of $E$ seems to increase linearly as the $\mathrm{Si}_{3} \mathrm{~N}_{4}$ content in the interphase increases, and $E$ follows the Voigt rule of mixtures. ${ }^{13}$ The $E$ value measured from the load-deflection plots followed a similar trend, and moduli measured using both techniques agreed within $6 \%$.

\section{(2) Strength and Energy Absorption}

Four-point flexural tests were performed using a screwdriven machine operated in displacement control (Model 4483, Instron, Danvers, MA). All tests were performed using a fully articulating testing jig with free-rolling pins using an outer span of $40 \mathrm{~mm}$ and an inner span of $20 \mathrm{~mm}$. Data were collected using a computerized data-acquisition system at a rate of 5 points per second. Strength and WOF were measured on unnotched specimens at a crosshead displacement rate of 0.5 $\mathrm{mm} / \mathrm{min}$. Prior to testing, the specimens were polished to a 3 $\mu \mathrm{m}$ finish using resin-bonded diamond wheels (TBW, Furlong, PA) on the tensile surface and on one side surface. The edges of the specimen on the tensile surface were also chamfered. Tests were interrupted when the specimen fractured completely, the retained load dropped below $5 \mathrm{~N}$, or the crosshead displacement exceeded $1 \mathrm{~mm}$, whichever came first. The strength of the specimens was calculated using standard elasticbeam equations, whereas the WOF value was calculated by dividing the total area under the load-deflection curve by twice the cross-sectional area of the specimen. For specimens that fractured catastrophically, the WOF value was reported as zero.

The nominal stress ${ }^{\dagger \dagger}$ on the tensile surface for representative specimens is plotted versus crosshead deflection for unnotched specimens in Fig. 2. In general, the load remains linear up to the peak load for all the materials. After the peak load, some of the specimens continue to retain load at specimen deflections as large as $1 \mathrm{~mm}$. The greatest degree of load retention is observed in the materials with the lowest $\mathrm{Si}_{3} \mathrm{~N}_{4}$ content in the interphase; no load retention is observed following the peak load when the $\mathrm{Si}_{3} \mathrm{~N}_{4}$ content in the interphase exceeds $25 \%$.

The nominal strength and WOF are plotted in Fig. 3 as a function of the $\mathrm{Si}_{3} \mathrm{~N}_{4}$ content in the interphase. Although there is scatter in the nominal strengths, there does not seem to be a systematic change in strength with increasing $\mathrm{Si}_{3} \mathrm{~N}_{4}$ content in the interphase. However, the WOF value decreases precipitously as the $\mathrm{Si}_{3} \mathrm{~N}_{4}$ content in the interphase increases. The slight decrease in strength and WOF for the specimens that

${ }^{\dagger}$ The nominal stress is calculated using standard elastic-beam theory, assuming elastic isotropy. It is recognized that the true stress is dependent on the local microstructure (i.e., the stiffer $\mathrm{Si}_{3} \mathrm{~N}_{4}$ bears higher stress) and that the stress state is altered when cracking occurs anywhere in the beam. 


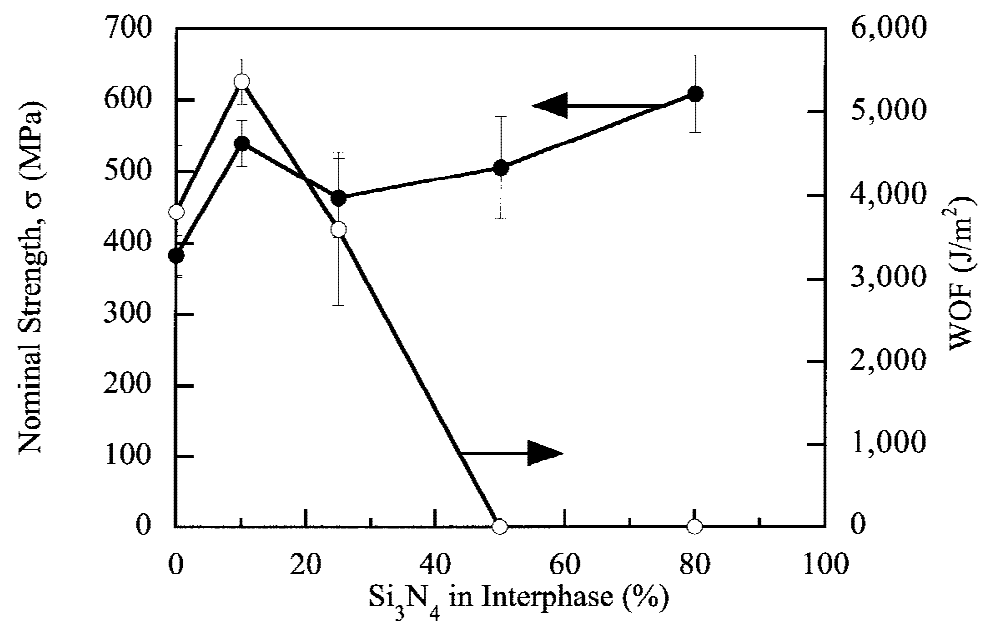

Fig. 3. Nominal strength $(\sigma)$ and work-of-fracture (WOF), plotted versus the $\mathrm{Si}_{3} \mathrm{~N}_{4}$ content in the interphase.

contain no $\mathrm{Si}_{3} \mathrm{~N}_{4}$ in the interphase is probably due to manufacturing defects that were present in this billet.

\section{(3) Crack Deflection and Delamination Cracking}

SEM micrographs of the side surfaces of representative specimens after testing are shown in Figs. 4(a)-(d). Cracks are deflected between almost every layer until the $\mathrm{Si}_{3} \mathrm{~N}_{4}$ content in the interphase is increased to $80 \mathrm{vol} \%$; no crack deflection is observed in the specimen that contains $80 \mathrm{vol} \% \mathrm{Si}_{3} \mathrm{~N}_{4}$ in the interphase. In Fig. 5, a higher-magnification micrograph of the side surface is shown for a specimen that contains $50 \mathrm{vol} \%$ $\mathrm{Si}_{3} \mathrm{~N}_{4}$ in the interphase. This micrograph shows that, although crack deflection is apparent between $\mathrm{Si}_{3} \mathrm{~N}_{4}$ layers, the lengths of the delamination cracks are extremely short $(<100 \mu \mathrm{m})$.

The lengths of the delamination cracks in the other materials also are dependent on the composition of the interphase between the $\mathrm{Si}_{3} \mathrm{~N}_{4}$ layers. For example, long delamination cracks are observed between almost every $\mathrm{Si}_{3} \mathrm{~N}_{4}$ layer in the materials that contain 0 vol\% and $10 \mathrm{vol} \% \mathrm{Si}_{3} \mathrm{~N}_{4}$ in the interphase. However, the delamination distances decrease rapidly as the $\mathrm{Si}_{3} \mathrm{~N}_{4}$ content in the interphase is increased to 25 and 50 vol\% $\mathrm{Si}_{3} \mathrm{~N}_{4}$ in the interphase. The delamination cracks in these materials are observed to kink out of the interphase after propagating only a short distance. Unfortunately, it is difficult to quantify
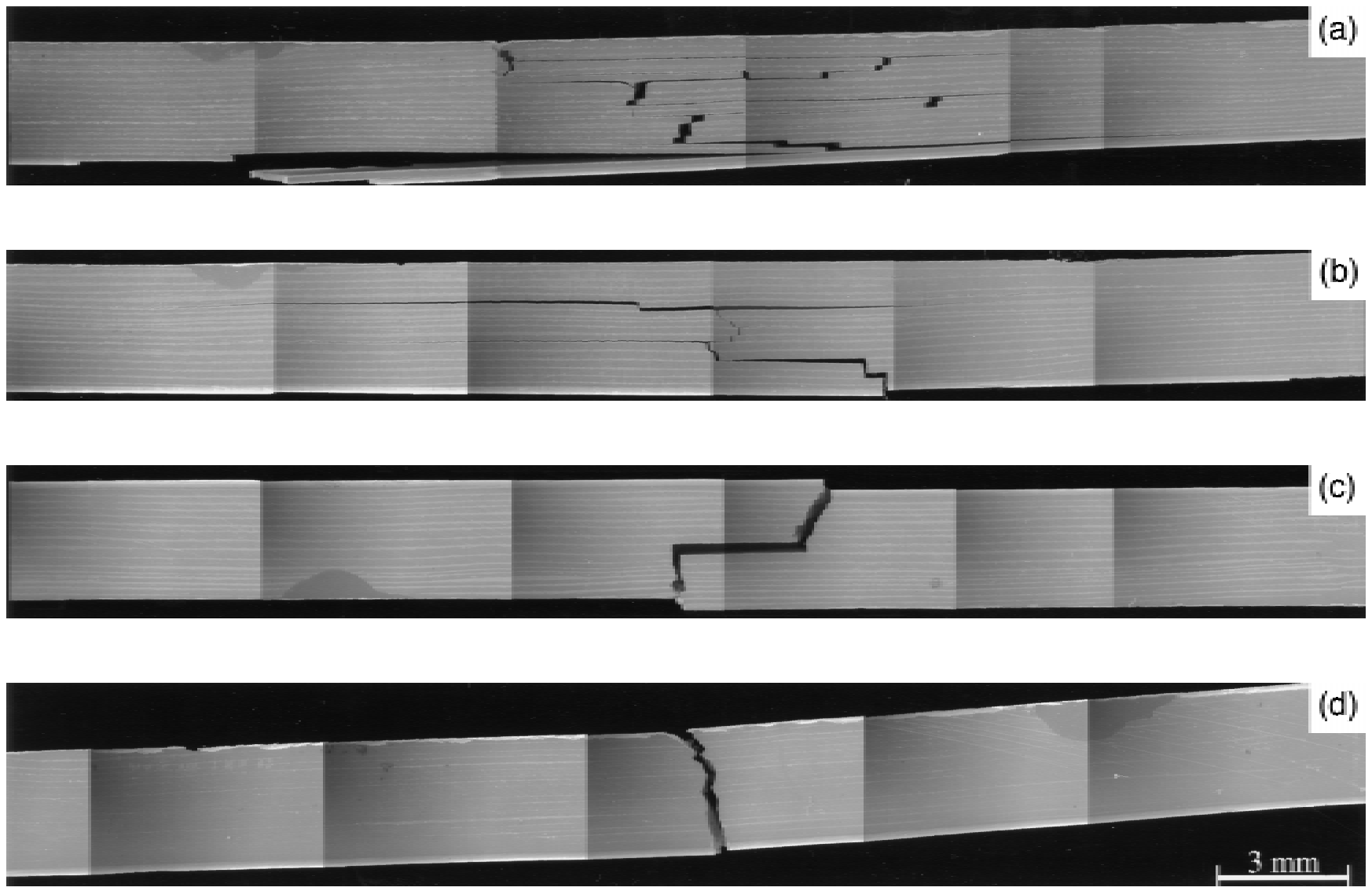

Fig. 4. SEM micrographs of the side surface of flexural specimens containing (a) 10, (b) 25, (c) 50, and (d) 80 vol\% $\mathrm{Si}_{3} \mathrm{~N}_{4}$ in the interphase (after testing). Crack deflection is observed for specimens containing up to $50 \mathrm{vol} \% \mathrm{Si}_{3} \mathrm{~N}_{4}$ in the interphase. 


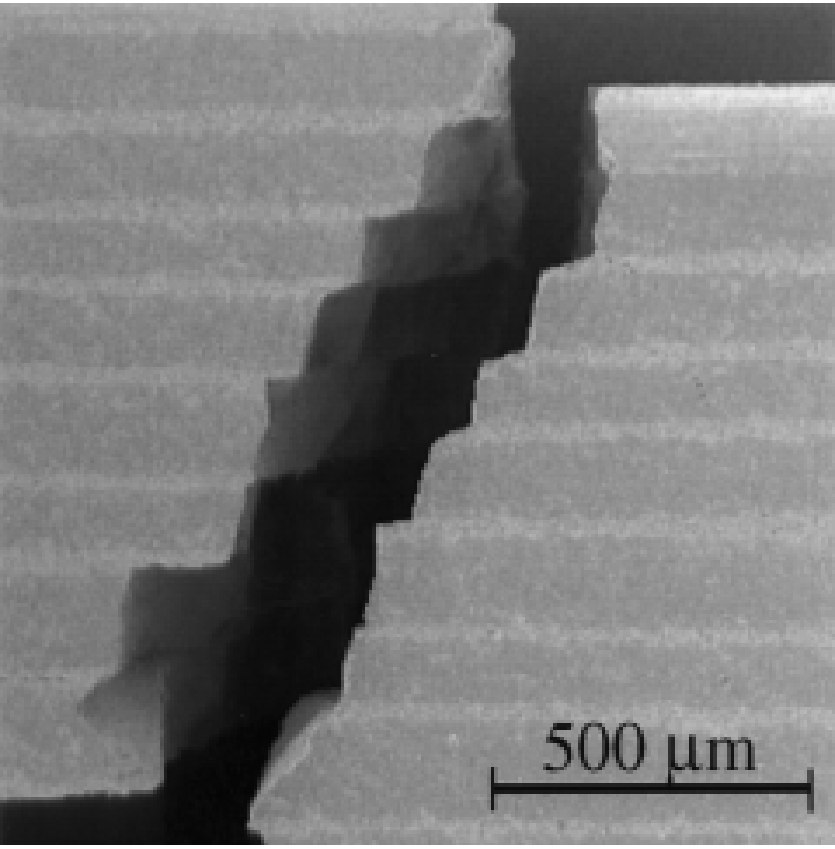

Fig. 5. Higher-magnification SEM micrograph of the side surface of one of the specimens containing $50 \mathrm{vol} \% \mathrm{Si}_{3} \mathrm{~N}_{4}$ in the interphase, showing crack deflection at many of the $\mathrm{BN}$-containing interphases; however, the length of the delamination cracks are limited by cracking kinking.

the length of delamination cracks, because it is not easy to discern the crack tip in the BN interphase. However, a measure of the delamination distances can be obtained from the distance between through-thickness cracks in adjacent $\mathrm{Si}_{3} \mathrm{~N}_{4}$ layers. Schematic illustrations that show how these distances were measured are shown in Fig. 6. A cumulative distribution plot of delamination crack lengths is shown in Fig. 7 for each of the materials. The delamination distances are longest in the materials that contain $0 \mathrm{vol} \%$ and $10 \mathrm{vol} \% \mathrm{Si}_{3} \mathrm{~N}_{4}$ in the interphase. Consistent with the micrographs shown in Fig. 4, the delamination distances decrease markedly as the $\mathrm{Si}_{3} \mathrm{~N}_{4}$ content is increased.

A higher-magnification SEM micrograph of a throughthickness crack in a $\mathrm{Si}_{3} \mathrm{~N}_{4}$ layer that is impinging on a $\mathrm{BN}$

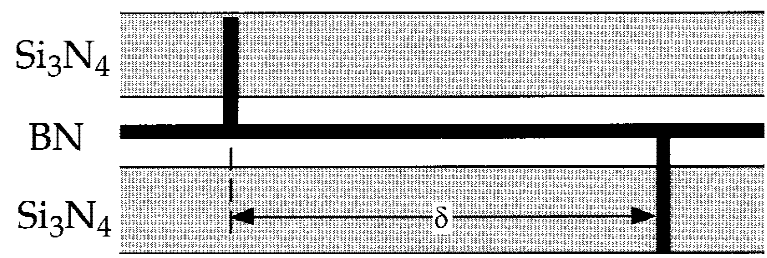

(a)

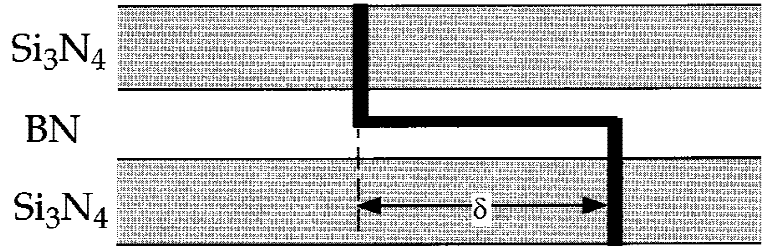

(b)

Fig. 6. Schematic illustration showing how the distance between through-thickness cracks, $\delta$, was measured in materials that exhibited (a) delamination cracking and (b) crack kinking.

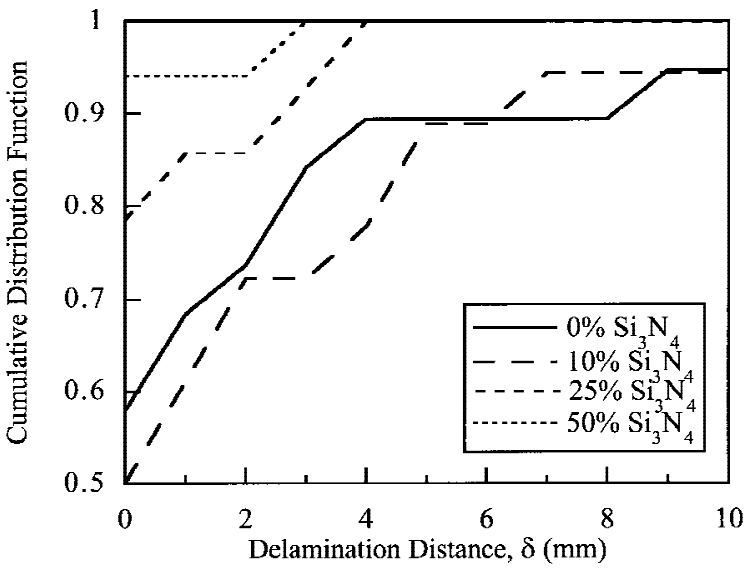

Fig. 7. Spacing between through-thickness cracks in the $\mathrm{Si}_{3} \mathrm{~N}_{4}$ layers, measured for each of the materials; the cumulative fraction of the delamination cracks shorter than a given value are shown for each of the materials.

interphase is shown in Fig. 8(a). It is clear from this micrograph that crack deflection occurs within the $B N$ interphase near the $\mathrm{Si}_{3} \mathrm{~N}_{4} / \mathrm{BN}$ interface, rather than at the interface between the two materials. As shown in Fig. 8(b), subsequent delamination cracking also occurs within the $\mathrm{BN}$ interphase. The crack often meanders within the $\mathrm{BN}$ interphase, and no systematic trend, with respect to the crack path, could be discerned. The location of the crack within the BN-containing interphase did not seem to change as $\mathrm{Si}_{3} \mathrm{~N}_{4}$ was added to the interphase.

\section{(4) Interfacial Fracture Resistance}

Interfacial fracture resistance was measured using notched flexure tests, following the analysis of Charalambides et al. ${ }^{14}$ from the steady-state load necessary to propagate a delamination crack. One advantage of performing this test on multilayer specimens rather than on simple bilayer specimens is that residual stresses present due to thermal mismatch between the $\mathrm{BN}$ and $\mathrm{Si}_{3} \mathrm{~N}_{4}$ do not influence the measurement of the interfacial fracture resistance. ${ }^{15}$ The applied phase angle $(\Psi=$ $\left.\tan ^{-1}\left[K_{\mathrm{II}} / K_{\mathrm{I}}\right]\right)$ was calculated assuming that there was a sufficient number of layers so that the elastic properties of a single interphase did not influence the overall elastic properties of the specimen. Thus, the measured Young's modulus $(E)$ of the composite was used to calculate $\Psi$. For the current experiments, the notch was cut to approximately the center of the specimen, which resulted in a $\Psi$ value of $42^{\circ}$. The interfacial fracture resistance, $\Gamma_{\mathrm{i}}$, was calculated from ${ }^{14}$

$$
\Gamma_{\mathrm{i}}=\frac{3 P^{2}(S-L)^{2}\left(1-v^{2}\right)}{2 E b^{2}}\left[\frac{1}{H^{3}(1-\eta)^{3}}-\frac{1}{H^{3}}\right]
$$

where $P$ is the applied load at which the delamination crack extends, $v$ the Poisson's ratio of the composite, $E$ the in-plane Young's modulus of the composite, $b$ the width of the specimen, $H$ the height of the specimen, and $\eta$ the distance from the tensile surface of the beam to the delamination crack divided by the total height of the beam. $S$ and $L$ are the outer span and the inner span in the four-point test fixture, respectively.

Representative load-deflectometer-displacement curves are shown for notched specimens tested in four-point flexure in Figs. 9(a)-(d) for materials that contain 10, 25, 50, and $80 \mathrm{vol} \%$ $\mathrm{Si}_{3} \mathrm{~N}_{4}$ in the interphase. For materials with $<50$ vol\% $\mathrm{Si}_{3} \mathrm{~N}_{4}$ in the interphase, the crack paths are generally similar. The load increases linearly until a crack is initiated from the notch and propagates into the closest $\mathrm{BN}$-containing interphase, where the crack is deflected and arrests. Subsequent specimen deflection causes the delamination cracks to propagate stably in the interphase to either side of the notch at an almost-constant load. 

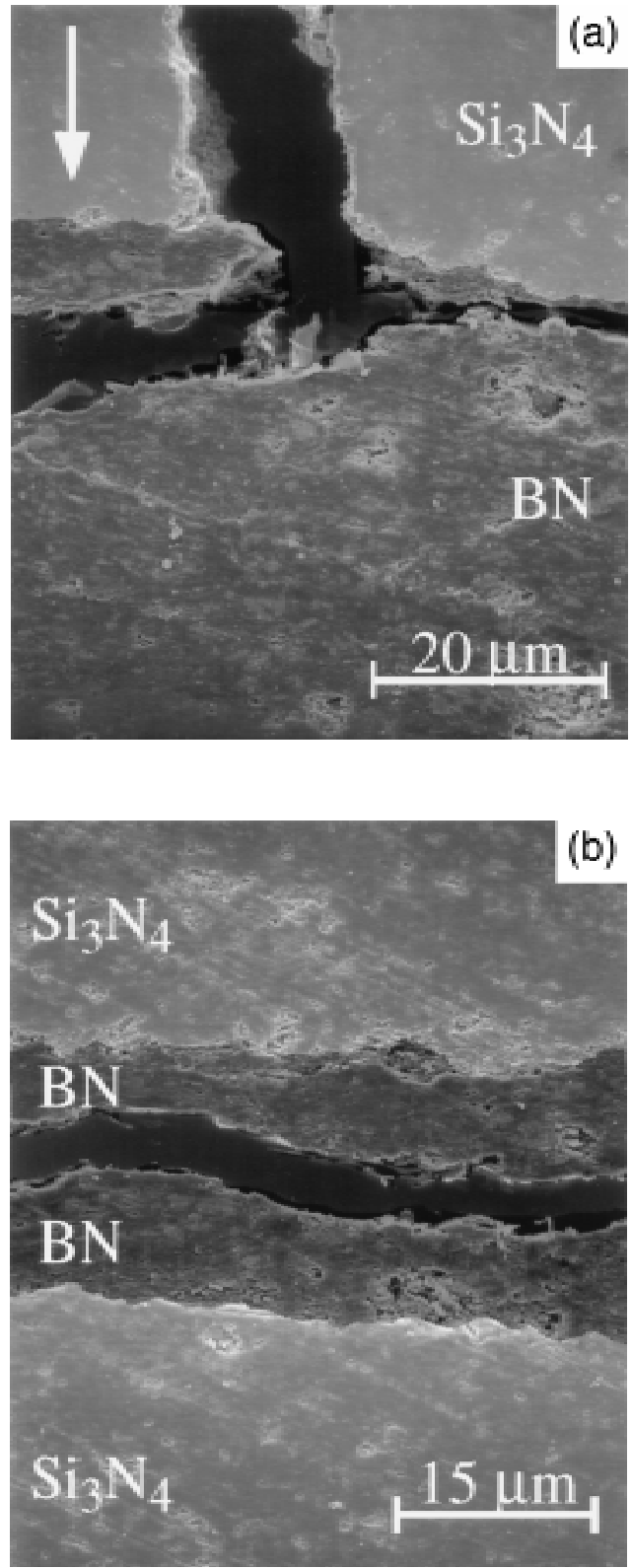

Fig. 8. Path of (a) a crack impinging on a $\mathrm{Si}_{3} \mathrm{~N}_{4} / \mathrm{BN}$ interface and (b) a delamination crack after crack deflection has occurred. Note that crack deflection and crack propagation both occur within the $\mathrm{BN}$ interphase. The arrow in Fig. 8(a) indicates the direction of crack growth.

Eventually, the delamination crack arrests when the crack reaches the end of the inner loading span. As specimen deflection is continued, the load again begins to increase linearly until the uncracked portion of the beam cannot support the applied load anymore. A crack then initiates in the $\mathrm{Si}_{3} \mathrm{~N}_{4}$ layer closest to the delamination crack and propagates until it is deflected in the next $\mathrm{BN}$-containing interphase. This process is repeated until the through-thickness cracks propagate completely through the specimen.

For specimens that contain $50 \mathrm{vol} \% \mathrm{Si}_{3} \mathrm{~N}_{4}$ in the interphase, when cracks initiated from the notch, they were deflected only to one side of the notch before being arrested. Subsequent specimen deflection caused the delamination crack to grow stably only a short distance before kinking out of the interphase and through the neighboring $\mathrm{Si}_{3} \mathrm{~N}_{4}$ layer. This kinking process was repeated through successive layers as loading continued, which resulted in a zig-zag crack patch similar to that shown in Fig. 5 for an unnotched bar of the same material. Unlike the materials that contained less $\mathrm{Si}_{3} \mathrm{~N}_{4}$ in the interphase, the loaddeflection curve for this material exhibited a peak in load when the first delamination crack propagated; subsequent crack growth occurred at lower loads. Specimens that contained 80 vol\% $\mathrm{Si}_{3} \mathrm{~N}_{4}$ in the interphase failed catastrophically with no crack deflection.

The interfacial fracture resistance $\left(\Gamma_{\mathrm{i}}\right)$ is plotted as a function of $\mathrm{Si}_{3} \mathrm{~N}_{4}$ content in the interphase in Fig. 10. The interfacial fracture resistance increases linearly, from $\sim 30 \mathrm{~J} / \mathrm{m}^{2}$ to $90 \mathrm{~J} / \mathrm{m}^{2}$, as the $\mathrm{Si}_{3} \mathrm{~N}_{4}$ content in the interphase is increased from $0 \mathrm{vol} \%$ to $50 \mathrm{vol} \%$. Because no crack deflection occurred in the specimens that contained $80 \mathrm{vol} \% \mathrm{Si}_{3} \mathrm{~N}_{4}$ in the interphase, the interfacial fracture resistance could not be determined using the four-point delamination test. Figures 11(a) and (b) show SEM micrographs of the interfacial fracture surfaces for specimens that contain 10 and $50 \mathrm{vol} \% \mathrm{Si}_{3} \mathrm{~N}_{4}$ in the interphase. Because delamination cracking occurred within the weak interphases, both $\mathrm{BN}$ and $\mathrm{Si}_{3} \mathrm{~N}_{4}$ are visible on the fracture surfaces. Qualitatively, the ratio of $\mathrm{BN}$ to $\mathrm{Si}_{3} \mathrm{~N}_{4}$ visible on the fracture surfaces for all the materials is approximately equal to the ratio of $\mathrm{BN}$ to $\mathrm{Si}_{3} \mathrm{~N}_{4}$ in the interphases themselves, which may explain why the interfacial fracture resistance seems to follow a rule of mixtures; the energy required to fracture the interphase should be the sum of the energies required to separate the constituent phases.

\section{(5) Frictional Sliding Resistance}

Because frictional sliding can be a potent source of energy dissipation in fiber-reinforced composites, ${ }^{16}$ the frictional sliding resistance, $\tau_{\mathrm{s}}$, was assessed in these layered ceramics as a function of the composition of the interphase using a technique developed by Kovar and Thouless. ${ }^{12}$ This test was performed using the same specimen geometry as that in the flexural strength measurements. The side of the specimen was notched, which allowed a wedge to be inserted. The wedge was driven into the notch until the specimen split completely through a weak interphase. The specimen was then reassembled and loaded in three-point flexure. When the shear stress along the cracked interface exceeded the sliding resistance $\tau_{\mathrm{s}}$, slipping along the interface occurred. By measuring the specimen deflection using an LVDT that was placed in contact with the specimen, the onset of slipping and, hence, $\tau_{\mathrm{s}}$ was determined from the point where a change in compliance is observed during loading or unloading. The sliding resistance $\tau_{\mathrm{s}}$ was calculated from the hysteresis area for a series of load-unload cycles taken over a range of loads. The hysteresis area, $W$, is related to the normalized sliding resistance, $T$ (equal to $\tau_{\mathrm{s}} / E$ ), by

$$
W=\frac{E b H^{2} \Sigma^{3} T[T+3 \Pi \eta(\eta-1)]}{12\left[\eta(\eta-1)\left(1-3 \eta+3 \eta^{2}\right)\right]}
$$

where $\Sigma$ is the normalized span between the outer loading points $(\Sigma=S / H)$ and $\Pi$ is the normalized load range $(\Pi=$ $\left.\left(P_{\max }-P_{\min }\right) /(E b H)\right)$. Because the solution of Eq. (2) for $\tau_{\mathrm{s}}$ yields two real roots, the physically correct root must be determined by examination of the experimental data. The normal pressure applied to the interface during the test has been calculated by dividing the mean load during a given load-unload cycle by the area of the interface that is sliding (the width of the specimen multiplied by its length). Because of the high interfacial fracture resistance in the material that contained $80 \mathrm{vol} \%$ $\mathrm{Si}_{3} \mathrm{~N}_{4}$ in the interphase, specimens made from this material did not split cleanly through the interphase during precracking. As a result, frictional sliding resistance could not be measured in this material.

All the materials exhibited some degree of hysteresis energy dissipation during testing. Representative hysteresis loops taken over different load ranges are shown for the material that contains 50 vol\% $\mathrm{Si}_{3} \mathrm{~N}_{4}$ in the interphase in Fig. 12. As was observed in all the materials, the hysteresis loops have a tendency to be wider at higher loads, which implies that the sliding resistance increases as the normal pressure on the interface 

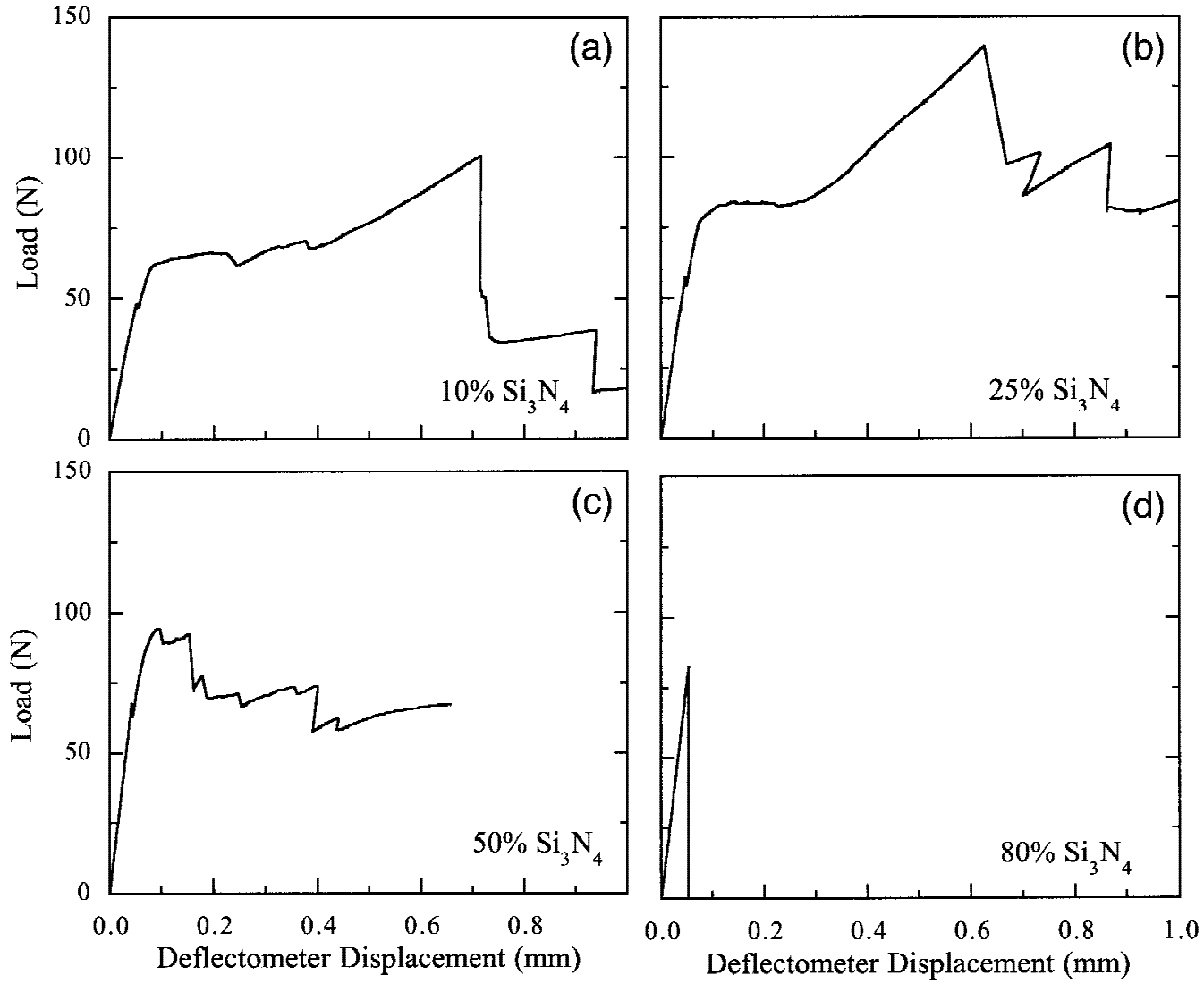

Fig. 9. Load-LVDT-deflectometer-displacement plot for notched specimens containing (a) 10 , (b) 25 , (c) 50 , and (d) 80 vol\% $\mathrm{Si}_{3} \mathrm{~N}_{4}$ in the interphase. Propagation of the initial delamination crack occurs at an almost-constant load in Figs. 9(a)-(c).

increases. This observation indicates that there is some coulombic contribution to the frictional sliding resistance $\tau_{\mathrm{s}}$. Based on a simple coulombic model in which the sliding resistance is given by

$$
\tau_{\mathrm{s}}=\tau_{\mathrm{o}}+\mu p
$$

where $\tau_{\mathrm{o}}$ is the intrinsic sliding resistance at zero normal pressure, $p$ the normal pressure, and $\mu$ a coulombic coefficient of friction, it was found that the friction coefficients for the materials generally increase as the $\mathrm{Si}_{3} \mathrm{~N}_{4}$ content in the interphase increases. Values for $\mu$ varied from 0.17 to 0.76 as the $\mathrm{Si}_{3} \mathrm{~N}_{4}$ content in the interphase was increased.

At a given load range, the widest hysteresis loops were ob-

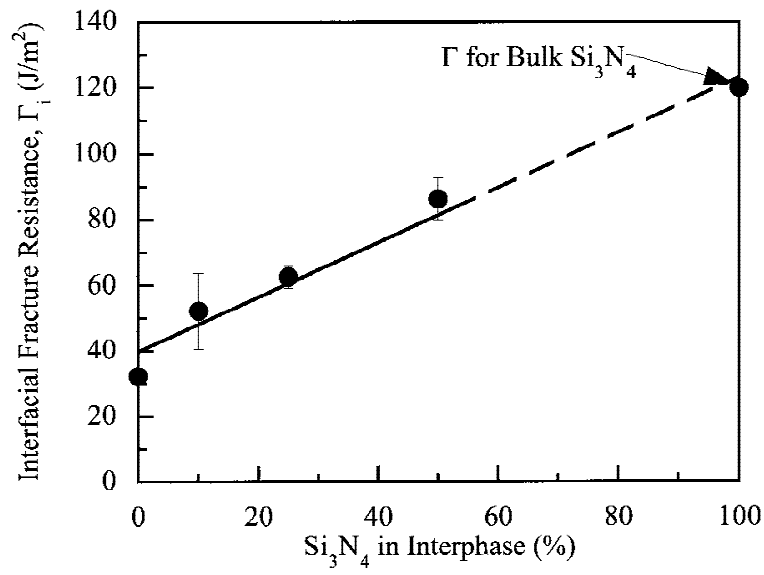

Fig. 10. Interfacial fracture resistance $\left(\Gamma_{\mathrm{i}}\right)$, plotted versus $\mathrm{Si}_{3} \mathrm{~N}_{4}$ content in the interphase; the fracture resistance for bulk $\mathrm{Si}_{3} \mathrm{~N}_{4}$ is also plotted. served for the material that contained 50 vol\% $\mathrm{Si}_{3} \mathrm{~N}_{4}$ in the interphase, whereas the materials that contained 0,10 , and 25 vol\% $\mathrm{Si}_{3} \mathrm{~N}_{4}$ in the interphase had narrower loops. Frictional sliding resistance, $\tau_{\mathrm{s}}$, is plotted as a function of the normal applied pressure on the interface for specimens that contained differing values of $\mathrm{Si}_{3} \mathrm{~N}_{4}$ in the interphase in Fig. 13. The solid lines represent the best fit, based on a least-squares linear regression. Only the material that contained $50 \mathrm{vol} \% \mathrm{Si}_{3} \mathrm{~N}_{4}$ in the interphase exhibited significantly higher sliding resistance; the sliding resistance in this material is $2-3$ times that of the other materials.

The fact that BN, a well-known solid lubricant, is present on the sliding surfaces may explain why the value of $\tau_{\mathrm{s}}$ is very low in these materials. Because BN platelets are significantly larger than the $\mathrm{Si}_{3} \mathrm{~N}_{4}$ grains, the roughness of the fracture surfaces decreases as the $\mathrm{Si}_{3} \mathrm{~N}_{4}$ content in the interphase increases (see Figs. 11(a) and (b)). Contrary to previous observations made on fiber-reinforced composites, ${ }^{17,18}$ however, the sliding resistance decreased as the roughness of the sliding surfaces increased. The presence of lubricious $\mathrm{BN}$ on the interface seems to have a much-larger role than the interfacial roughness in the determination of the sliding resistance in these materials.

\section{Discussion}

Comparison of the delamination cracking morphologies for the $\mathrm{Si}_{3} \mathrm{~N}_{4} / \mathrm{BN}$ layered ceramics shown in Figs. 4(a)-(d) with the interfacial fracture resistance shows that, in materials with very high interfacial fracture resistance values $\left(>80 \mathrm{~J} / \mathrm{m}^{2}\right)$, no crack deflection is observed and very little energy is absorbed. Specimens with moderate interfacial fracture resistance values $\left(50-80 \mathrm{~J} / \mathrm{m}^{2}\right)$ exhibit crack deflection; however, the delamination cracks are short because the delamination cracks kink out of the interphase. These specimens also do not absorb much energy. Extensive delamination cracking and high energy ab- 

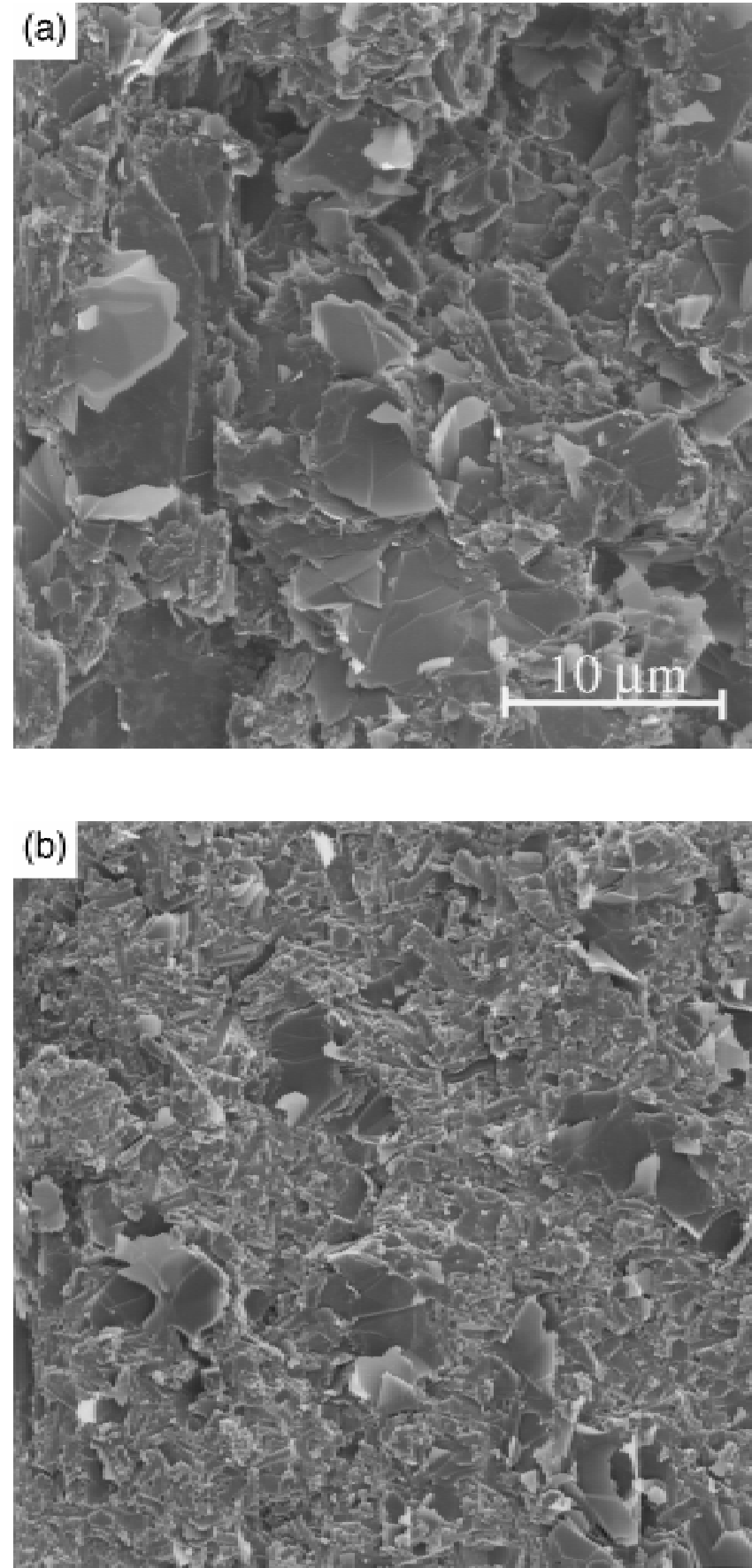

Fig. 11. SEM micrographs, each at the same magnification, of the interfacial fracture surfaces for specimens containing (a) 10 and (b) 50 $\mathrm{vol} \% \mathrm{Si}_{3} \mathrm{~N}_{4}$ in the interphase, taken prior to the sliding experiments (the large platelike grains are $\mathrm{BN}$, whereas the finer grains are $\mathrm{Si}_{3} \mathrm{~N}_{4}$ ).

sorption are observed only in materials that have the lowest interfacial fracture resistance $\left(30-50 \mathrm{~J} / \mathrm{m}^{2}\right)$.

These observations suggest that the energy-absorption capability of a material is not determined merely by whether or not crack deflection occurs. Rather, the extent of energy absorption is primarily influenced by the crack path after the initial crack deflection occurs. Specifically, the energy-absorption capability is greatly reduced when the delamination cracks kink out of the interphase after traveling only a short distance. Thus, determination of the nature of the transition between delamination cracking and crack kinking is essential to the development of layered ceramics that have high energy-absorption capability. There are at least two possible explanations for the crack kinking behavior observed in these layered ceramics: (i) an

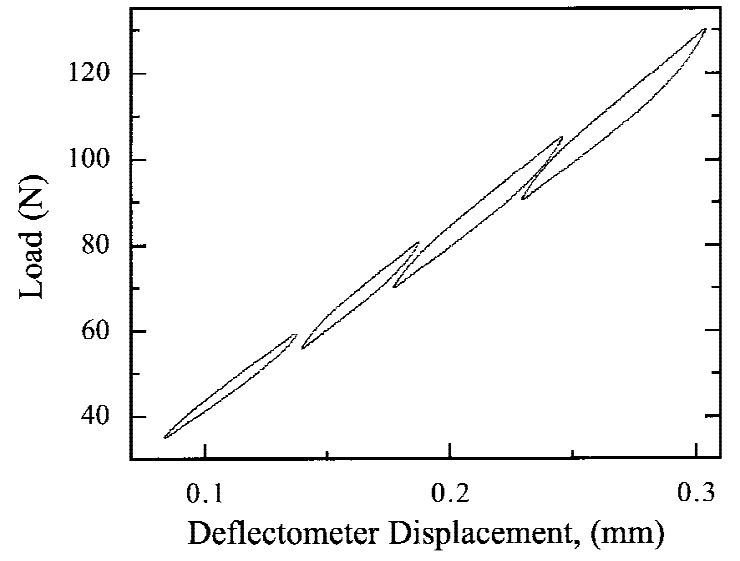

Fig. 12. Several hysteresis loops, shown over different loading ranges, for the material containing $50 \mathrm{vol} \% \mathrm{Si}_{3} \mathrm{~N}_{4}$ in the interface; the width of the loops increases as the load increases.

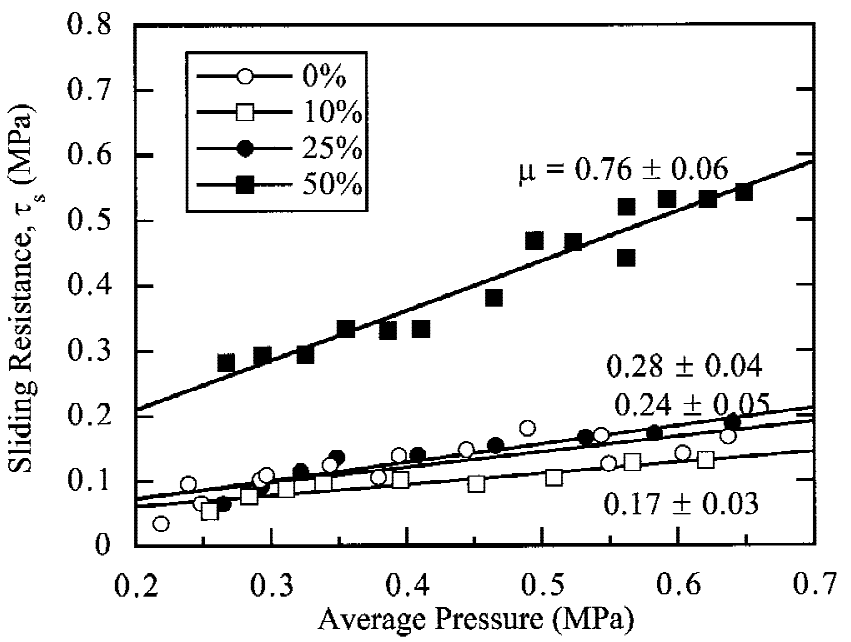

Fig. 13. Frictional sliding resistance $\left(\tau_{\mathrm{s}}\right)$, plotted versus the normal pressure on the interphase for specimens with varying $\mathrm{Si}_{3} \mathrm{~N}_{4}$ content of the interphase; the mean and standard deviation of the coefficient of friction $(\mu)$ are also shown.

increasing interfacial resistance with delamination crack length ( $R$-curve behavior), and (ii) the presence of defects along the interface that draw the delamination crack out of the interphase.

It has been suggested that delamination cracks can kink out of an interface under certain conditions when the interfacial fracture resistance increases as the crack extension increases. ${ }^{19}$ Such $R$-curve behavior has been observed during the growth of delamination cracks in polymer/ceramic systems ${ }^{20}$ as well as other all-ceramic layered systems. ${ }^{21,22} R$-curve behavior in ceramics is usually the result of frictional sliding that occurs in the crack wake during extension. ${ }^{23}$ In the $\mathrm{Si}_{3} \mathrm{~N}_{4} / \mathrm{BN}$ system examined in this study, however, the measured sliding resistance was extremely low (see Fig. 13) and $R$-curve behavior was not observed during the growth of delamination cracks. ${ }^{*}$ Thus, $R$-curve behavior does not contribute to crack kinking in this material system.

Another explanation that has been previously proposed to explain crack kinking behavior involves flaws in the $\mathrm{Si}_{3} \mathrm{~N}_{4}$

If the interfacial fracture resistance increases as the crack extension increases, the load necessary to propagate a delamination crack will also increase. The plateau load that is observed during delamination cracking in these materials (see Fig. 9) indicates that $R$-curve behavior does not occur. 
layers that are oriented perpendicular or almost perpendicular to the interface. If these flaws are sufficiently large, they can draw the delamination crack out of the interphase and into a $\mathrm{Si}_{3} \mathrm{~N}_{4}$ layer, which causes the delamination crack to kink. ${ }^{19} \mathrm{~A}$ theoretical treatment of such a problem has been previously proposed by $\mathrm{He}$ et $a l .{ }^{24}$ and has been used here to predict the critical interfacial flaw size necessary to induce crack kinking.

He et al $^{24}$ suggested that the driving force for crack kinking is provided by the in-plane stress (T-stress) that acts parallel to the interface at the delamination crack tip and is influenced by the size of interfacial flaws. This stress can result from the applied loads or from residual stresses that may be present due to thermal expansion mismatch between the layers. In the case of the $\mathrm{Si}_{3} \mathrm{~N}_{4} / \mathrm{BN}$ system, extensive microcracking has been observed in the BN layers prior to testing. ${ }^{7}$ If the T-stress contributes to crack kinking in this material system, it must result from the applied loads, because microcracking should act to relieve most of the residual stress due to thermal mismatch between the $\mathrm{Si}_{3} \mathrm{~N}_{4}$ and the $\mathrm{BN}$.

An analytical calculation of the T-stress caused by the applied loads is quite complex for the delamination specimen used in the current study. However, it is possible to calculate an upper-bound limit to the T-stress using simple beam-bending equations. Because only the uncracked portion of the beam carries load, the normal stress in this portion of the beam can be calculated from the moment necessary to propagate the delamination crack using Eq. (1). To a first approximation, this in-plane stress is the T-stress that results from the applied moment. Therefore, the T-stress, $\sigma_{\mathrm{o}}$, is given by

$$
\sigma_{\mathrm{o}}=\left[\frac{6 \Gamma_{\mathrm{i}} E}{H \eta(\eta-1)\left(3 \eta-\eta^{2}-3\right)\left(1-v^{2}\right)}\right]^{1 / 2}
$$

This is an approximation because, in reality, the uncracked portion of the beam also carries some load at a distance far from the delamination crack tip. Thus, this calculation yields an upper bound to the T-stress. For this specimen geometry, the calculated value of the T-stress varies slightly with the position of the delamination crack within the specimen. However, given the nature of this calculation, this variation was neglected and the T-stress was calculated assuming $\eta=0.5$.

Besides the T-stress, there are several other parameters that influence the critical flaw size for crack kinking, such as the flaw orientation, with respect to the interface, and the elastic mismatch between the materials on either side of the interface. To simplify the calculation, it was assumed that all flaws were oriented perpendicular to the interface. It was also necessary to compute the Dundurs' parameters, $\alpha$ and $\beta$, from the Young's modulus $(E)$ and Poisson's ratios $(\nu)$ of the individual layers. Previous measurements of $E$ for this composition of $\mathrm{Si}_{3} \mathrm{~N}_{4}$ gave a value of $320 \mathrm{GPa},{ }^{11}$ and the value of $v$ has been reported as being 0.27. Literature values of $E$ and $v$ for $\mathrm{BN}$ have been reported as $22 \mathrm{GPa}$ and 0.32 , respectively. ${ }^{25}$

The results of this calculation are plotted in Fig. 14 and show the dependence of the critical flaw size required to cause crack kinking on the interfacial fracture resistance. Based on the strength (which, from Fig. 2, did not vary substantially as the composition of the interphase was adjusted) and fracture resistance of the $\mathrm{Si}_{3} \mathrm{~N}_{4}$ layers, the maximum flaw size in these layers is $\sim 45 \mu \mathrm{m}$. At this critical flaw size, the transition from delamination cracking to crack kinking is predicted from Fig. 14 to occur when $\Gamma_{\mathrm{i}} / \Gamma_{\mathrm{Si}_{3} \mathrm{~N}_{4}}=0.4$ or $\Gamma_{\mathrm{i}}=50 \mathrm{~J} / \mathrm{m}^{2}$. The observed crack deflection behavior shown in Figs. 4(a)-(d) seems to agree well with this prediction. At very high values of fracture resistance $\left(\Gamma_{\mathrm{i}}>80 \mathrm{~J} / \mathrm{m}^{2}\right)$, no crack deflection was observed. At moderate values of the interfacial fracture resistance $\left(\Gamma_{\mathrm{i}}=50-80 \mathrm{~J} / \mathrm{m}^{2}\right)$, crack deflection occurred; however, most of the delamination crack lengths were very short due to crack kinking. Extensive delamination cracking was only observed in the materials that had very low interfacial fracture resistance values $\left(\Gamma_{\mathrm{i}}=30-50 \mathrm{~J} / \mathrm{m}^{2}\right)$. It is also important to note that some

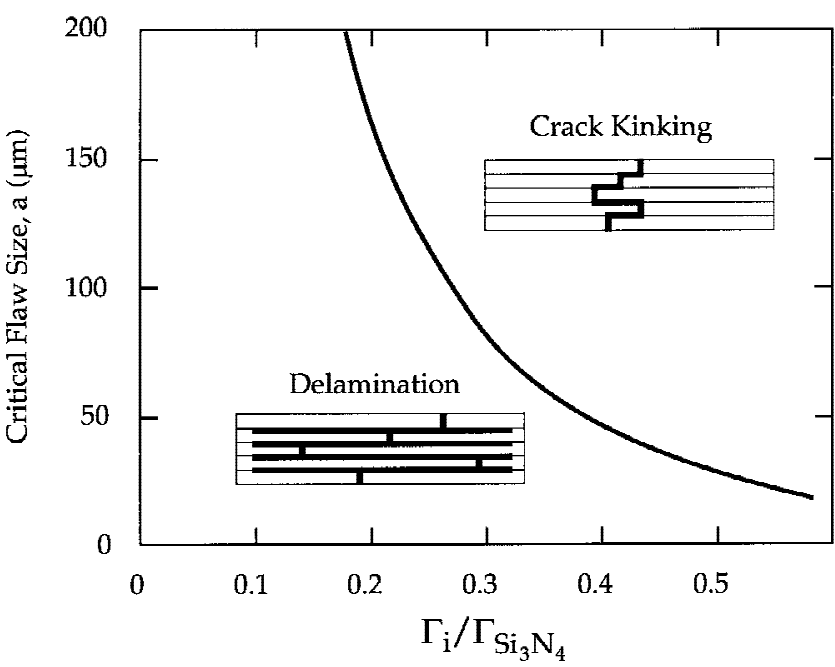

Fig. 14. Ratio of the fracture resistance of the interphase to fracture resistance of the $\mathrm{Si}_{3} \mathrm{~N}_{4}$ layer $\left(\Gamma_{\mathrm{i}} / \Gamma_{\mathrm{Si}_{3} \mathrm{~N}_{4}}\right)$, plotted versus the critical flaw size necessary to induce crack kinking $(a)$.

of the materials exhibited a combination of delamination cracking and crack kinking (see Figs. 7 and 9(b) and (c)). The probability that crack kinking occurred along a given interphase increased as the interfacial fracture resistance increased. The statistical nature of crack kinking is consistent with the notion that crack kinking is controlled by the probability of encountering a suitable interfacial defect.

Despite the qualitative agreement between the observed behavior and the crack kinking model that was presented, there are several reasons why caution should be taken in directly applying this model to the $\mathrm{Si}_{3} \mathrm{~N}_{4} / \mathrm{BN}$ system. For example, the analysis of He et al. ${ }^{24}$ that was used to calculate the conditions for crack kinking assumed that crack deflection occurs at the interface between two layers rather than within the interphase, as was observed in this system (see Fig. 8(a)); this suggests that, in the $\mathrm{Si}_{3} \mathrm{~N}_{4} / \mathrm{BN}$ system, crack deflection is not controlled by the fracture resistance of the interface between $\mathrm{Si}_{3} \mathrm{~N}_{4}$ and $\mathrm{BN}$, but rather by the weak $\mathrm{BN}$ interphase itself. The appropriate material properties that control crack deflection in this case are the ratio of the fracture resistance in the $\mathrm{BN}$ parallel to the interface, compared to the fracture resistance of the $\mathrm{BN}$ in a direction perpendicular to the interface, as well as the elastic anisotropy of BN in these directions. Based on SEM observations, the $\mathrm{BN}$ consists of well-aligned platelets that have a thickness of $\sim 0.1-0.5 \mu \mathrm{m}$ and a length and width of $\sim 5-10 \mu \mathrm{m}$. Texture measurements on similar fibrous monolithic laminates using XRD confirm that the BN is highly textured; ${ }^{26}$ thus, it is expected that there should be anisotropy in the fracture resistance as well as in the elastic properties. Unfortunately, it is not possible to measure the fracture resistance of $\mathrm{BN}$ perpendicular to the interface, because cracks that are driven in this direction inevitably deflect and grow parallel to the interface.

The fact that crack propagation occurs in the $\mathrm{BN}$ interphase rather than at the $\mathrm{Si}_{3} \mathrm{~N}_{4} / \mathrm{BN}$ interface may also influence this calculation. Although flaws in the $\mathrm{Si}_{3} \mathrm{~N}_{4}$ layers can act to draw the crack out of the interphase, it is also possible that local regions of high interfacial resistance within the $\mathrm{BN}$ interphase (e.g., a $\mathrm{Si}_{3} \mathrm{~N}_{4}$ particle or a misaligned $\mathrm{BN}$ platelet) may impede the delamination crack and cause it to kink. Schematic illustrations of these two cases are shown in Fig. 15. Additional complications also result if one considers the pre-existing microcracks that have been observed in the $\mathrm{BN}$ layers ${ }^{7}$ and their influence on crack deflection and subsequent delamination. These factors emphasize the need for the development of morerealistic models that can account for interfacial defects as well as the anisotropy of the interphase. 


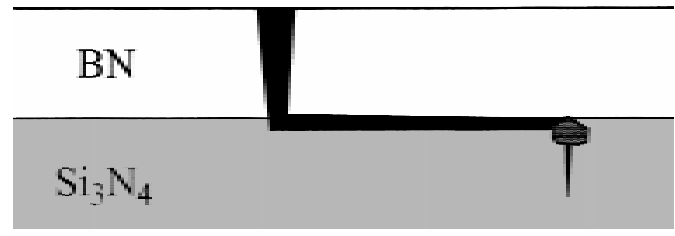

(a)

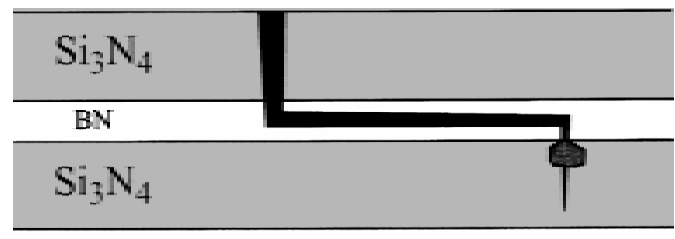

(b)

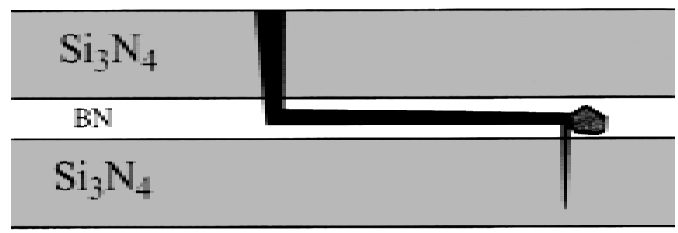

(c)

Fig. 15. Schematic depiction of the possible reasons for crack kinking. The idealized situation considered by He et $\mathrm{al}^{24}$ is shown in Fig. 15 (a), where a crack is growing on the interface between $\mathrm{Si}_{3} \mathrm{~N}_{4}$ and BN before being drawn out of the interface by a flaw in the $\mathrm{Si}_{3} \mathrm{~N}_{4}$ layer. However, in the $\mathrm{Si}_{3} \mathrm{~N}_{4} / \mathrm{BN}$ system, delamination cracking occurs within the BN layer until the crack is drawn out of the interphase by a flaw in the $\mathrm{Si}_{3} \mathrm{~N}_{4}$ (Fig. 15(b)) or it is driven out of the interphase by a local region of high interfacial fracture resistance (Fig. 15(c)).

\section{Conclusions}

Silicon nitride $\left(\mathrm{Si}_{3} \mathrm{~N}_{4}\right)$ layered ceramics separated by weak interphases that contain a mixture of boron nitride $(\mathrm{BN})$ and $\mathrm{Si}_{3} \mathrm{~N}_{4}$ were manufactured and tested in flexure. Strengths in excess of $500 \mathrm{MPa}$ and work-of-fracture (WOF) values that exceed $5000 \mathrm{~J} / \mathrm{m}^{2}$ were achieved. The strength was insensitive to the composition of the interphase; however, the WOF decreased dramatically as the $\mathrm{Si}_{3} \mathrm{~N}_{4}$ content in the interphase was increased. Observations of the crack path revealed that the energy-absorption capacity of these materials was related directly to the length of delamination cracks. In materials that exhibited low energy absorption, the delamination crack lengths were limited by crack kinking.

The crack-kinking behavior that was observed as the $\mathrm{Si}_{3} \mathrm{~N}_{4}$ content in the interphase was increased was attributed to interfacial flaws that act to draw the delamination crack out of the interphase. A relationship was derived that related the interfacial fracture resistance and interfacial flaw size to the tendency for crack kinking to occur. Crack kinking was predicted to be favored at high relative values of the interfacial fracture resistance. Agreement between this model and the observed crack paths was good.

These results indicate that promotion of crack deflection is not a sufficient condition to achieve high energy absorption in layered ceramics. Rather, high energy absorption requires that delamination cracks propagate a substantial distance. Long delamination distances are favored when the interfacial fracture resistance is low, the flaw size in the layers is small, and the fracture resistance of the layers is high. At very low values of the interfacial fracture resistance, increasing the interfacial fracture resistance causes more energy to be dissipated through the creation of interfacial crack area. However, if the interfacial fracture resistance is too high, crack kinking will reduce the delamination crack area. This observation suggests that, for a given material system, there is an optimum interfacial fracture resistance that maximizes the energy-absorption capability, and this optimum value is determined by the transition from delamination cracking to crack kinking.

\section{References}

${ }^{1}$ W. J. Clegg, K. Kendall, N. McN. Alford, T. W. Button, and J. D. Birchall, "A Simple Way to Make Tough Ceramics,', Nature (London), 357 [Oct. 4] 455-57 (1990).

${ }^{2}$ A. J. Phillipps, W. J. Clegg, and T. W. Clyne, "Fracture Behavior of Ceramic Laminates in Bending-II. Comparison of Model Predictions with Experimental Data," Acta Metall. Mater., 41 [3] 819-27 (1993).

${ }^{3}$ C. A. Folsom, F. W. Zok, and F. F. Lange, "Flexural Properties of Brittle Multilayer Materials: II, Experiments,' J. Am. Ceram. Soc., 77 [8] 2081-87 (1994)

${ }^{4}$ H. Liu and S. H. Hsu, "Fracture Behavior of Multilayer Silicon Nitride/ Boron Nitride Ceramics," J. Am. Ceram. Soc., 79 [9] 2452-57 (1996).

${ }^{5}$ G. A. Danko, D. Popovic, K. Stuffle, B. H. King, J. W. Halloran, J. W. Holmes, and D. F. Hasson, 'Commercial Development of Fibrous Monolithic Ceramics,' Ceram. Eng. Sci. Proc., 16 [5] 673-80 (1995).

${ }^{6}$ G. E. Hilmas, G. A. Brady, and J. W. Halloran, "SiC and $\mathrm{Si}_{3} \mathrm{~N}_{4}$ Fibrous Monoliths: Non-brittle Fracture from Powder Processed Ceramics Produced by Coextrusion"; pp. 609-14 in Ceramic Transactions, Vol. 51, Ceramic Process ing Science and Technology. Edited by H. Hausner, G. L. Messing, and S.-I. Hirano. American Ceramic Society, Westerville, OH, 1994.

${ }^{7}$ D. Kovar, B. H. King, R. W. Trice, and J. W. Halloran, "Fibrous Monolithic Ceramics,'” J. Am. Ceram. Soc., 80 [10] 2471-87 (1997).

${ }^{8}$ J. Cook and J. E. Gordon, "A Mechanism for the Control of Crack Propagation in All-Brittle Systems,', Proc. R. Soc. London, 282, 508-20 (1964).

${ }^{9}$ M.-Y. He and J. W. Hutchinson, "Crack Deflection at an Interface between Dissimilar Elastic Materials,', Int. J. Solids Struct., 25 [9] 1053-67 (1989).

${ }^{10}$ W. Lee and W. J. Clegg, "The Deflection of Cracks at Interfaces," Key Eng. Mater., 116-117, 193-208 (1996).

${ }^{11}$ D. Kovar, G. A. Brady, M. D. Thouless, and J. W. Halloran, “'Interfacial Fracture between Boron Nitride and Silicon Nitride and Its Applications to the Failure Behavior of Fibrous Monolithic Ceramics"; pp. 243-48 in Materials Research Society Symposium Proceedings, Vol. 409, Instability Dynamics, Scaling, and Ductile/Brittle Behavior. Edited by R. L. Blumberg Selinger, J. J. Mecholsky, A. E. Carlsson, and E. R. Fuller Jr. Materials Research Society, Pittsburgh, PA, and Boston, MA, 1996.

${ }^{12}$ D. Kovar and M. D. Thouless, "Simple Method for Measuring Frictional Sliding Resistance and Energy Dissipation in Layered Ceramics, " J. Am. Ceram. Soc., 80 [3] 673-79 (1997).

${ }^{13}$ W. D. Kingery, H. K. Bowen, and D. R. Uhlmann, Introduction to Ceramics, 2nd Ed.; p. 774. Wiley, New York, 1976.

${ }^{14}$ P. G. Charalambides, J. Lund, A. G. Evans, and R. M. McMeeking, "A Test Specimen for Determining the Fracture Resistance of Bimaterial Interfaces," J. Appl. Mech., 56 [3] 77-82 (1989).

${ }^{15}$ J. W. Hutchinson and Z. Suo, "Mixed Mode Cracking in Layered Materials"'; pp. 64-191 in Advances in Applied Mechanics, Vol. 29. Edited by J. W. Hutchinson and T. Y. Wu. Academic Press, San Diego, CA, 1992.

${ }^{16}$ A. G. Evans and F. W. Zok, "Review-The Physics and Mechanics of FibreReinforced Brittle Matrix Composites," J. Mater. Sci., 29, 3857-96 (1994).

${ }^{17}$ T. A. Parthasarathy, D. R. Barlage, P. D. Jero, and R. J. Kerans, "Effect of Interfacial Roughness Parameters on the Fiber Pushout Behavior of a Model Composite," J. Am. Ceram. Soc., 77 [12] 3232-36 (1994).

${ }^{18}$ T. J. Mackin, P. D. Warren, and A. G. Evans, "Effects of Fiber Roughness on Interface Sliding in Composites,' Acta Metall. Mater., 40, 1251-57 (1992).

${ }^{19}$ M. D. Thouless, H. C. Cao, and P. A. Mataga, "Delamination from Surface Cracks in Composites,' J. Mater. Sci., 24, 1406-12 (1989).

${ }^{20} \mathrm{~S}$. Hashemi, A. J. Kinloch, and G. Williams, "Mixed-Mode Fracture in Fiber-Polymer Composite Laminates"; pp. 143-68 in Composite Materials: Fatigue and Fracture, Vol. 3, ASTM Special Technical Publication 1110. Edited by T. K. O'Brien. American Society for Testing and Materials, Philadelphia, PA, 1991.

${ }^{21}$ O. Sbaizero, P. G. Charalambides, and A. G. Evans, 'Delamination Cracking in a Laminated Ceramic-Matrix Composite,', J. Am. Ceram. Soc., 73 [7] 1936-40 (1990)

${ }^{22}$ P. E. D. Morgan and D. B. Marshall, "Ceramic Composites of Monazite and Alumina,"' J. Am. Ceram. Soc., 78 [6] 1553-63 (1995).

${ }^{23}$ S. J. Bennison and B. R. Lawn, "Role of Interfacial Grain-Bridging Sliding Friction in the Crack-Resistance and Strength Properties of Nontransforming Ceramics," Acta. Metall., 37 [10] 2659-71 (1989).

${ }^{24}$ M.-Y. He, A. Bartlett, A. G. Evans, and J. W. Hutchinson, "Kinking of a Crack out of an Interface: Role of In-Plane Stress,' J. Am. Ceram. Soc., 74 [4] 767-71 (1991)

${ }^{25}$ J. H. Edgar, "Crystal Structure, Mechanical Properties and Thermal Properties of BN"; pp. 7-21 in Properties of Group III Nitrides. Edited by J. H. Edgar. INSPEC, London, U.K., 1994.

${ }^{26}$ R. J. Moon, K. J. Bowman, D. Kovar, and J. W. Halloran, "Preferred Orientation in $\mathrm{Si}_{3} \mathrm{~N}_{4} / \mathrm{BN}$ Fibrous Monoliths," to be submitted to J. Am. Ceram. Soc. 